Hill, Andrew P. ORCID:

https://orcid.org/0000-0001-6370-8901 (2017) Real and imagined perils: A reply to Stoeber and Gaudreau (2017). Personality and Individual Differences, 108. pp. 220-224.

Downloaded from: http://ray.yorksj.ac.uk/id/eprint/1955/

The version presented here may differ from the published version or version of record. If you intend to cite from the work you are advised to consult the publisher's version: http://www.sciencedirect.com/science/article/pii/S0191886916312053

Research at York St John (RaY) is an institutional repository. It supports the principles of open access by making the research outputs of the University available in digital form. Copyright of the items stored in RaY reside with the authors and/or other copyright owners. Users may access full text items free of charge, and may download a copy for private study or non-commercial research. For further reuse terms, see licence terms governing individual outputs. Institutional Repository Policy Statement

\title{
RaY
}

Research at the University of York St John

For more information please contact RaY at ray@yorksj.ac.uk 
Hill, A. (in press). Real and imagined perils: A reply to Stoeber and Gaudreau (2017). To appear in Personality and Individual Differences. Accepted 13-12-2016.

Real and imagined perils: A reply to Stoeber and Gaudreau (2017)

Andrew P. Hill

York St John University, UK

Running head: Perils and Perfectionism

Manuscript accepted: 13-12-2016

Word count: 6196

Andrew P. Hill, $\mathrm{PhD}$

Faculty of Health and Life Sciences

York St. John University

Lord Mayor's Walk

York, YO31 7EX

UK

e-mail:a.hill@yorksj.ac.uk 


\section{Real and imagined perils: A reply to Stoeber and Gaudreau (2017)}

I reply to Stoeber and Gaudreau's (2017) recent commentary on my paper outlining the "perils of partialling" when examining multidimensional perfectionism (Hill, 2014). In my original paper I argued that the conceptual meaning of one of the two superordinate dimensions of perfectionism, perfectionistic strivings, may change once its relationship with the other superordinate dimension, perfectionistic concerns, is controlled for or partialled (i.e., when residual perfectionistic strivings is created and examined). In light of this possibility, I argued that it may be inappropriate or "perilous" to draw conclusions regarding perfectionistic strivings based on residual perfectionistic strivings. Stoeber and Gaudreau disagree. In responding to their commentary, I explain how and why our two perspectives differ. I argue that, despite their view to the contrary, there is sufficient reason to be concerned regarding the conceptual meaning of residual perfectionistic strivings. In addition, I also argue that Stoeber and Gaudreau have misunderstood where the peril lies when using partial correlations and have concluded that my paper called for a rejection of the examination of partial correlations when this was not the case. 
I am grateful to Stoeber and Gaudreau for taking the time to respond to my paper (Hill, 2014) and receive their response in the collegial manner it was intended. I strongly believe in the value of open scholarly debate. It is an excellent means of encouraging critical reflection, progressing knowledge, and directing future research. Therefore, in the spirit of scholarly debate, and so to clarify a number of important issues, I provide my own rejoinder to Stoeber and Gaudreau's paper.

The aim of my response is to identify and explain issues on which we agree and disagree based upon the arguments I provided in my initial paper and the arguments Stoeber and Gaudreau provided in their riposte. My response does not address all of the issues they raised. Rather, it focuses on the issues which I consider key in terms of understanding our two perspectives. Hopefully readers find my rejoinder useful in terms of drawing their own conclusions regarding the "perils" of partialling.

\section{Background}

Before directly addressing each issue I consider important, some explanation of my motives for writing the initial paper may provide a helpful backdrop for the current disagreement. The paper to which Stoeber and Gaudreau's commentary applies was partly motivated by increasing concerns I had regarding the conclusions of a number of peerreviewed papers that appeared at the time. I was particularly concerned by the certainty with which it was being concluded that perfectionistic strivings (PS) may be healthy or adaptive and the influence that this message may have on researchers and practitioners interested in perfectionism. Most notably, this included the conclusion of a paper that reviewed research in an area of especial interest to me, sport, which stated "only perfectionistic concerns are clearly maladaptive, whereas perfectionistic strivings may form part of a healthy striving for excellence" (Stoeber, 2011, p.1). 
My paper was also partly motivated by other concerns that research was beginning to progress at pace in my primary areas of interest (sport, dance, and exercise) while, to my mind, a number of fundamental questions remained unanswered. In particular, what was PS precisely, what was "perfectionistic" about this concept, and how was it different from conscientiousness or other motivational variables (e.g., achievement goals)? At the time, similar questions had received attention from others, including Flett and Hewitt $(2005,2006$, 2007), Greenspon (2000, 2008), and Hall (2006). However, efforts to answer these questions in sport had treated them as questions to be resolved by conceptual scrutiny. There were far fewer efforts to treat these questions as empirical questions to be resolved through the collection of primary data. Consequently, colleagues and I began a line of research that attempted to do so (Hill, Hall, \& Appleton, 2010, 2012).

As part of developing this line of research, I decided to examine what I considered to be a misstep in this area of research. Specifically, the conclusion that PS was healthy or adaptive was based largely on the adaptive and maladaptive relations of residual PS. That is, PS having controlled for or partialled its relationship with the other major dimension of perfectionism, perfectionistic concerns (PC). What is more, I believed that doing so was potentially problematic. I tested this assertion in the paper Stoeber and Gaudreau have responded to by contrasting the relationships of PS and residual PS with a range of variables. The findings of this study highlighted a range of differences between PS and residual PS and, I concluded, supported my assertion. My approach was based on an excellent paper by Lynam, Hoyle, and Newman (2006) in which they illustrated the interpretational difficulties, or perils, that can arise when using partialling to examine aggression and psychopathy. I was also encouraged by researchers who were highlighting similar issues when examining perfectionism (e.g., Molnar, Sadeva, Flett, \& Coautti, 2012; Powers, Koestner, Zuroff, 
Milyavskaya, \& Gorin, 2011), as well as researchers who had scrutinised other residual variables such as "shame-free-guilt" and "guilt-free-shame" (Elison, 2005).

\section{Issue 1: The conceptual meaning of residual PS}

The main assertion in my paper was that, following partialling, the conceptual meaning of PS may change and therefore residual PS is not an appropriate basis on which to draw conclusions regarding PS. The foundation of this argument was laid by Lynam et al (2006) who identify various factors that influence the degree of confidence with which one can make inferences about an unresidualised variable (PS) based on the residualised variable (residual PS). In addition to a number of other factors, Lynam et al emphasised the importance of "theoretical tightness." When the variables to be partialled are poorly defined, broad and vague (as opposed to well-defined, narrow and clear), interpretation of the residual variable is more difficult as it is less obvious what the new residualised variable represents (Lynam et al., 2006). In my paper I argued that PS was not conceptually and operationally well-defined because PS has historically been defined and operationalised in a broader manner than is sometimes appreciated. Specifically, it was evident that many researchers consider PS to include more than just the act of striving and includes elements of selfevaluation that are shared with PC. In this regard, I highlighted two features, conditional selfacceptance and self-criticism, that I considered important in terms of possible ambiguity surrounding PS (and ultimately the conceptual differences between PS and residual PS once $\mathrm{PC}$ is controlled for).

In their response, Stoeber and Gaudreau argue that "it is possible to define PS and PC without making reference to the[se] features," that "people can strive for perfection without making their self-worth contingent upon achieving perfection, or without criticizing themselves if they fail to reach perfection" and that these features are "better conceptualized 
as correlates of perfectionism to be studied separately from PS and PC" (p.380). They also present evidence from studies that they argued illustrated that while related, correlations are sufficiently low between conditional self-acceptance and PS and PC to suggest it is not a defining feature of either. Similarly, self-criticism is closely related only to PC but is not a defining feature of either PC or PS.

In regards to this issue, I do not believe Stoeber and Gaudreau have provided a convincing rebuttal to my concerns regarding the conceptual ambiguity surrounding PS or the potential for the conceptual meaning of PS to change following partialling. Their response is surprisingly sparse in this regard. They merely dismiss the assertion that self-criticism and conditional self-acceptance are defining features of PS and PC. They do not acknowledge or discuss the substantial debate and discussion surrounding PS that is evident in this area of research and is the basis for the concerns I raised (e.g., Flett \& Hewitt, 2002, 2006; Hall, 2006). Therefore, at this point, I see little reason to alter my initial perspective and remain unconvinced that there is not at least some ambiguity surrounding PS and, therefore, residual PS. For the benefit of those unfamiliar with this area of research, conceptual "fuzziness" has historically been one of the defining features of research examining perfectionism. In the opening chapter of their seminal book, for example, Flett and Hewitt (2002) listed 21 terms that have been used to define and describe perfectionism. Moreover, discussion and debate is ongoing regarding a range of definition and operationization issues pertaining to perfectionism (e.g., Flett \& Hewitt, 2007; Stairs, Smith, Zapolski, Combs, \& Settles, 2012; Stoeber, 2016). This is evident at superordinate and subordinate levels of perfectionism. When providing an overview of the hierarchical model of perfectionism, its superordinate dimensions are defined principally by the measures that serve as their indicators (subordinate dimensions). This is common practice and is the case in Stoeber and Gaudreau's paper ("perfectionistic striving...capture forms, aspects, and subordinate dimensions of 
perfectionism reflecting a self-oriented striving for perfection and exceedingly high personal standards”, p.379). Is superordinate perfectionistic strivings a theoretically grounded, tightly defined, construct? Or is it defined loosely and operationalized by the content of instruments designed to measure other things? As useful as I think the hierarchical model is in terms of providing a heuristic and common language in this area (very useful), I believe it is the latter.

The definition and operationalization of the two most common subordinate dimensions of PS are also subject to debate. Personal standards were conceived as "high personal standards of performance and the tendency to evaluate oneself based on performance" (Frost, Marten, Lahart, \& Rosenblate, 1990, p.54). In reanalysing the subscale designed to measure personal standards, Frost and colleagues later identified a number of items which measured contingent self-worth and suggested that these items were perhaps responsible for inconsistent findings regarding personal standards and adaptive/maladaptive functioning (DiBartolo, Frost, Chang, LaSota, \& Grills, 2004). Rather than disregarding these items, in concluding their paper they argued that "It would seem that personal standards are an essential part of the definition of the construct of perfectionism but only in as much as they are used by people as a gauge for determining their feelings about themselves" (DiBartolo et al., 2004, p.253). In addition, they recommended that future research compare outcomes for a "Pure Personal Standards" subscale (free from items measuring contingent self-worth) with their original Personal Standards subscale so to "explicate more carefully the relationship of standard setting to perfectionism's basic definition” (p.253). As far as I am aware, this work has yet to be undertaken.

Self-oriented perfectionism (SOP), another subordinate dimension of PS, has received similar scrutiny and even more intense debate. SOP is an especially complex dimension of perfectionism. This is evident in the writing of Hewitt and Flett (1991, 2007; Flett \& Hewitt, 2006) where the achievement striving associated with SOP is thought to conceal a strong 
vulnerability to motivational and psychological difficulties. Moreover, unlike more healthy patterns of achievement striving, SOP is described as entailing a more extreme form of compulsive striving or hyper-conscientiousness. In terms of its operationalization, like personal standards, there is evidence that the subscale used to measure it may include both elements of striving and something more problematic and similar to contingent self-worth (“importance of being perfect"). Research suggests that these two sub-facets have discernibly different patterns of adaptive and maladaptive relations (e.g., Campbell \& DiPaula, 2002; Hill et al., 2010; Stoeber, Kempe, \& Keogh, 2008). Based on the extensive writing of Flett and Hewitt, both sub-facets (not one over the other) are integral to understanding this particular subordinate dimension of perfectionism.

Such conceptual ambiguity is central to interpretational difficulties (and conceptual meaning) associated with residual PS. This is because PS shares, at least to some degree, selfevaluative features with PC. As such, in my initial paper I stated that partialling "removed variance" and, consequently, residual PS "lost" some of the features important in terms of understanding PS. Stoeber and Gaudreau found the notion that partialling removed variance particularly problematic because "this suggests that common aspects are removed and consequently the construct is changed" (p.382) and this is not the case. However, they illustrate nicely how this is the case. Specifically, in their Venn diagram presented by Stoeber and Gaudreau (2017, p. 381), and reproduced here in Figure 1, they identify how in regression analysis the relationship between residual PS and the criterion variable is captured only by section $b$, rather than section $b$ and $d$ as would be the case if PC was not in the model. Section $\mathrm{d}$ and whatever it represented in terms of commonality/covariance between PS, PC, and the criterion variable is "lost" (or perhaps, more accurately, often forgotten), when drawing conclusions regarding PS. The implications of this loss are readily apparent in 
research when PS is no longer a positive predictor of, say, anxiety once its relationship with PC has been controlled for and it is concluded that PS is unrelated to anxiety.

Although Stoeber and Gaudreau dismissed the significance of the empirical evidence of the relationships between PS and PC with conditional self-acceptance and self-criticism, in my opinion there is enough theoretical and empirical evidence that these are important common features of both PS and PC (if not defining features). Take Greenspon (2000, 2008), for example, who argued that "the essence of perfectionism is not striving for excellence, but rather, feelings of conditional self-acceptance" (2000, p.202) or Hewitt and Flett (1991) who suggested the possibility that self-criticism may be "a response common to all forms of perfectionism" (p.463). In the five studies I am aware of that have examined the relationship between SOP and self-acceptance correlations ranged from $r=-.17$ to -.46 (Flett, Russo, \& Hewitt, 1994; Flett, Besser, Davis, \& Hewitt, 2003; Scott, 2007; Hall, Hill, Appleton, \& Kozub, 2009; Hill, Hall, Appleton, \& Kozub, 2008). Similar sized correlations have also been found between SOP and various types of self-criticism (e.g., Dunkley \& Kyparissis, 2008; Hewitt \& Flett, 1991; Thompson, \& Zuroff, 2004). Though I did not discuss this in the original paper, there is also the concept of self-critical perfectionism for which self-criticism is considered integral (Dunkley, Zuroff, \& Blankstein, 2003). Self-critical perfectionism has recently been proposed to be part of a "big-three" perfectionism model (Smith, Saklofske, Stoeber, \& Sherry, in press). In the big-three model, self-criticism is a manifest indicator of self-critical perfectionism. Also of note, the big-three model includes "rigid perfectionism" that includes SOP and "self-worth contingencies" as its manifest indicators. Clearly, the features I identified are at the forefront of other researchers' minds when considering what others have described as "core perfectionism facets" (Smith et al., in press, p.5).

Stoeber and colleagues argue that accepting the argument that both PC and PS share an association with conditional self-acceptance and self-criticism may somehow steer 
perfectionism research in the "wrong direction" (p.380) and to a "return to one-dimensional conceptions of perfectionism of the 1980s" (p.381). This is because "if the characteristics PS share with PC are defining characteristics of PS - and if everything that is "perfectionistic" about PS is contained in the parts that PS share with PC - there would be little need to invest theoretical and empirical effort to study PS" (p380). I disagree. I do not believe my argument undermines the study of multidimensional perfectionism. This is because even after accounting for these features, there are still unique features of PS and PC that are important in terms of understanding perfectionism. For example, there is no personal striving element of PC or sense of pressure from others evident in PS. Indeed, the existence of these elements is a sound rationale for examining their unique effects. Stoeber and Gaudreau appear to be confusing one-dimensional conceptions of perfectionism (an amalgam of strivings and concerns) with PC and have concluded in error that the arguments I presented in my paper somehow preclude the study of the unique correlates, processes and outcomes of multidimensional perfectionism (see issue 2 below).

Perhaps the key difference in our perspective on this matter is that, as part of the same broad personality characteristic, I would expect PS and PC to share at least some features and that these features are core to what perfectionism is (and are the basis of the "perfectionistic" label). Moreover, so not to confuse PS with other similar constructs or to reduce it to simply an act of goal setting (as Stoeber and Gaudreau's example of students A and B appears to do, p.381), I think it important to locate the concept of PS in the classic writing on perfectionism that largely considered the striving associated with perfectionism to entail more than just high personal standards (e.g., Burns, 1980; Ellis, 1958; Missildine, 1963). Only by doing so can we ease concerns regarding the construct validity and discriminate validity of PS. By contrast, Stoeber and Gaudreau offer no explanation of why PS and PC are positively related, propose no features they might share, or explain differences between PS and other related 
forms of achievement strivings. Instead, Stoeber and Gaudreau appear to advocate a model of perfectionism whereby PS and PC are orthogonal as depicted in Figure 1 in Stoeber and Otto (2006, p.296). This does not accurately depict the relationship between PS and PC evident in research because they are presented as unrelated. It does, however, depict the relationship between residual PS and PC. I am sure the merits and shortcomings of an orthogonal model of multidimensional perfectionism would be keenly debated if the theoretical and empirical basis for such an approach was presented. In particular, whether, if this is the case, PS and PC are different personality traits rather than different dimensions of the same trait. In the meantime, researchers must be mindful of the positive relationship between PS and PC.

\section{Issue 2: Imagined perils and partialling}

Stoeber and Gaudreau state that in response to the finding that residual PS showed larger adaptive relations than PS, I concluded that "partialling PS is 'perilious' because removing PC from PS makes PS look more adaptive than they actually are” (p.381). Moreover, this implies the correlations associated with residual PS are "less real or less valid than those estimated with raw scores of PS" and portrays partialling as "statistical trickery that has no correspondence in (or relevance for) the real world"' (p.381).

On this issue, Stoeber and Gaudreau appear to believe that the "perils of partialling" to which the title of my paper refers pertains to using partialling generally. This is not the case. So to avoid any confusion, and to be clear, the peril lies in the interpretational difficulties that can arise following partialling when the intention is to use a residual variable (i.e., residual PS) as the basis for conclusions regarding a non-residual variable (i.e., PS). Partialling holds no perils in any general sense. In addition, partial correlations are not in any way less real, valid, or relevant to the real world. The subsequent exposition of partialling provided by Stoeber and Gaudreau is very useful. They go beyond what was provided in my 
paper by illustrating how partial correlations are influenced by both the size/direction of the relationships between PS and PC, as well as the size/direction of their respective relationships with a criterion variable. They also helpfully explain what is meant by "controlling" or "partialling" and how to interpret partial correlations (e.g., when individuals score the same level of PC, those with higher PS report lower anxiety). I am sure this will aid researchers in gaining a better understanding of partial correlations (and ease any concerns regarding any "trickery" associated with the approach). However, their exposition does not speak to the issue at hand. That is, whether knowing that individuals with the same level of PC but higher levels of PS (i.e., residual PS) are typically better off allows us to conclude that those with higher PS are typically better off. This was the issue at the centre of my paper.

\section{Issue 3: Baby and the bathwater}

Stoeber and Gaudreau suggest that by raising concerns regarding the use of partialling that I am in some way "rejecting" (p.380) an approach that has served perfectionism research so well over the last three decades and that this is "premature, if not entirely inappropriate" (pp.380).

On this issue, the suggestion that I reject the examination of partial correlations is incorrect. I stated clearly at the outset of the paper when initially discussing the perils of partialling that the perils (i.e., interpretational difficulties) described "are avoided if the research question focuses on combined, unique, or incremental predictive ability" (p.3). Moreover, the perils were confined only to specific circumstances whereby researchers sought to draw conclusions regarding the original variables (PS) based on the residualised variable. In fact, so concerned was I by the possibility that some readers may erroneously believe that I was discouraging the use of the approach, I also stated when concluding the paper that "research that has utilised partialling in this area has provided a number of 
conceptual and empirical advances in our understanding and will continue to do so" (p.12). Colleagues and I recently reiterated this point again elsewhere when discussing partialling, “...it is useful to reaffirm our belief in the obvious value of this approach and its continued use... without this approach, it would be not be possible to test important and interesting research questions regarding perfectionism (and across the field of psychology generally, of course). In particular, questions pertaining to the unique effects...characteristics, processes, and outcomes... would be missed without adopting such an approach" (p.143, Jowett, Mallinson, \& Hill, 2016).

If further evidence is required of the value I place in examining partial correlations, one only needs to consider the considerable time colleagues and I have recently spent calculating partial correlations as part of meta-analyses and systematic reviews (Hill \& Curran, 2016; Jowett et al., 2016). Consequently, rather than being at odds with Stoeber and Gaudreau regarding the importance of this approach, I am in agreement. The similarity of our positions on this issue is readily apparent when the statements from my previous work above are compared to Stoeber and Gaudreau own conclusions (“...partialling is essential if we want to understand the shared, unique, combined, and interactive relations of different dimensions of perfectionism", Stoeber et al., 2017, p.2). This hopefully also explains why, as pointed out by Stoeber and Gaudreau, colleagues and I have been happy to use this approach is the studies they cite (Hill \& Curran, 2016; Hill et al., 2008; Hill, Hall, Appleton, \& Murray, 2010). This includes adopting the $2 \times 2$ model of perfectionism (Hill, 2013; Hill \& Davis, 2014). My research group were among the first to adopt and test the $2 \times 2$ model in sport and have subsequently provided three of the seven published studies that exist in sport, dance, and exercise examining the model (see Gaudreau, 2016). We believe it is a valuable addition to this area of research and will continue to test the $2 \times 2$ model when our focus in on the interactive effects of PS and PC. 


\section{Issue 4: The case of perfectionistic concerns}

Stoeber and Gaudreau observed that “...researchers often ignore that partialling also affects the relations of PC" (p.12) and that they found the argument that the effect partialling has on PC was "less controversial" (Hill, 2014, p.310) to be "peculiar" (p.383). They offered three reasons why they believe the same concerns regarding partialling are not normally expressed for PC. Firstly, "The differences between PC and residual PC are usually not as large as those between PS and residual PS." Secondly, "PC do not become less maladaptive when PS are partialled out...[or] turn maladaptive relations into adaptive relations.”. Thirdly, "the effect that partialling has on PC — making PC more maladaptive-is consistent with the traditional view of perfectionism as a personality disposition that is essentially maladaptive... In contrast, the effect that partialling has on PS - making PS more adaptive - is inconsistent with the traditional view [of perfectionism]." What is more, they believe researchers "should take greater note of these effects" (p.384).

I am in agreement with Stoeber and colleagues that the influence partialling has on PC has received less attention and, to a lesser degree, why this is the case. The first two reasons they offer, to me, are reasonable grounds for paying less attention to residual PC. The higher degree of similarity between residual PC and PC and the more uniform changes in adaptive and maladaptive relations following partialling (decreasing adaptive relations and increasing maladaptive correlations) make the case of PC somewhat different from PS. Of note, you do not typically see changes in direction of the relationship between PC and criterion variables following partialling (as is the case of PS). As such, whereas within Lynam et al.'s (2006) framework the changes observed for PS following partialling pose the "greatest interpretative hazard" (p.330), the changes observed for PC are "the simplest and least problematic" (p.330). In agreement, the lesser influence of partialling on PC has even led some to argue 
that in some contexts "... it is relatively safe to examine perfectionistic concerns without statistically controlling for perfectionistic strivings" (Stoeber \& Damian, 2016, p. 267).

The lack of perceived controversy on my part also stemmed from issues that have caused the greatest disharmony among researchers and practitioners in this area. Unlike PS, there is little debate regarding PC or disagreement regarding the likely consequences of PC. I have yet to read any work that has not argued PC are problematic and suggest that PC need to managed/treated, as opposed to possibly encouraged. By contrast, casual perusal of research in this area will inevitably lead readers to numerous issues regarding healthy versus unhealthy perfectionism and particularly PS. These issues tend to feature heavily when researchers are tasked with summarising perfectionism research or given the opportunity to reflect on this area of research (e.g., Flett \& Hewitt, 2016; Hall, 2016; Sirois \& Molnar, 2016). In sum, these two issues seem to me to be a reasonable basis on which to describe the effect partialling has on PC to be "less controversial."

In terms of reconciling findings from partialling with a traditional view of perfectionism, from my experience researchers have not typically found it difficult to accept findings that residual PS is associated with desirable and adaptive relations. These findings are quite clear. The difficulty lies in making conceptual sense of PS and therefore residual PS. As a backdrop to resolving this difficulty, numerous peer-reviewed papers and book chapters have been dedicated to explaining the achievement striving associated with perfectionism and explaining why this is more likely to be unhealthy than healthy (e.g., Hall, 2016; Hall, Hill, \& Appleton, 2012; Flett \& Hewitt, 2016). This work includes careful explanation of mediating and moderating factors that need to be taken into account when considering the likely implications of perfectionism, generally, and PS, specifically. By contrast, in response, there have been few attempts to explain why this is not the case, why PS are adaptive, and how PS are different from other similar constructs. In the absence of 
such explanations, there is a danger that we will come to be guided by "naked empiricism" rather than theory and logical reasoning when considering the likely consequences of perfectionism.

\section{Concluding comments}

My paper on the perils of partialling in context of multidimensional perfectionism was intended to stimulate discussion and critical reflection among researchers interested in perfectionism. I note that in addition to Stoeber and Gaudreau's thoughtful response, there is evidence that as a consequence of my paper researchers have become more mindful of the perils of partialling and careful in the conclusions they are making regarding PS (e.g., Rice, Richardson, \& Ray, 2016; Smith et al., 2016; Flett \& Hewitt, 2014). This includes work by Stoeber and colleagues (Madigan, Stoeber, \& Passfield, 2015, 2016; Stoeber, Kobori, \& Brown, 2014). While there are areas of disagreement between my positon and the position of Stoeber and Gaudreau on a number of issues relating to PS (but seemingly not so on partialling generally), I am sure they would agree that this more discerning approach is a positive development. Likewise, I believe their paper will encourage others to reflect on their current practice and improve understanding of perfectionism. However, despite the clear value of their response, I remain steadfast in the belief that partialling is perilous if residual PS is used as the basis of conclusions regarding PS. 


\section{References}

Burns, D. D. (1980). The perfectionist's script for self-defeat. Psychology Today, 14, 34-52.

Campbell, J. D., \& Di Paula, A. (2002). Perfectionistic self-beliefs: Their relation to personality and goal pursuit. In G. L. Flett \& P. L. Hewitt (Eds.), Perfectionism: Theory, research, and treatment (pp. 181-198). Washington, DC: American Psychological Association.

DiBartolo, P.M., Frost, R.O., Chang, P., LaSota, M., \& Grills, A.E. (2004). Shedding light on the relationship between personal standards and psychopathology: The case for contingent self-worth. Journal of Rational-Emotive \& Cognitive-Behavior Therapy, 22, 241-254.

Dunkley, D. M., \& Kyparissis, A. (2008). What is DAS self-critical perfectionism really measuring? Relations with the five-factor model of personality and depressive symptoms. Personality and Individual Differences, 44, 1295-1305.

Dunkley, D. M., Zuroff, D. C., \& Blankstein, K. R. (2003). Self-critical perfectionism and daily affect: dispositional and situational influences on stress and coping. Journal of Personality and Social Psychology, 84, 234-252.

Elison, J. (2005). Shame and guilt: A hundred years of apples and oranges. New Ideas in Psychology, 23, 5-32.

Ellis, A. (1957). How to Live With a Neurotic: At Work and at Home. New York, NY: Crown. 
Flett, G. L., Besser, A., Davis, R. A., \& Hewitt, P. L. (2003). Dimensions of perfectionism, unconditional self-acceptance, and depression. Journal of Rational-Emotive and Cognitive-Behavior Therapy, 21, 119-138.

Flett, G. L., \& Hewitt, P. L. (2002). Perfectionism and maladjustment: An overview of theoretical, definitional, and treatment issues. In G. L. Flett \& P. L. Hewitt (Eds.), Perfectionism: Theory, Research and Practice (pp. 33-62). Washington, DC: American Psychological Association.

Feltt, G. L., \& Hewitt, P. L. (2005). The perils of perfectionism in sports and exercise. Current Directions in Psychological Science, 14, 14-18.

Flett, G. L., \& Hewitt, P. L. (2006). Positive versus negative perfectionism in psychopathology: A Comment on Slade and Owens's Dual Process Model. Behavior Modification, 30, 472-495.

Flett, G. L., \& Hewitt, P. L. (2007). When does conscientiousness become perfectionism. Current Psychiatry, 6, 49-64.

Flett, G. L., \& Hewitt, P. L. (2014). “The perils of perfectionism in sport” revisited: Toward a broader understanding of the pressure to be perfect and its impact on athletes and dancers. International Journal of Sport Psychology, 45, 395-407.

Flett, G. L., \& Hewitt, P. L. (2016). Reflections on perfection and the pressure to be perfect in athletes, dancers, and exercisers: A focus on perfectionistic reactivity in key situations and life contexts. In A. P. Hill (Ed.), The Psychology of Perfectionism in Sport, Dance, and Exercise (pp. 296-319). London: Routledge. 
Flett, G. L., Russo, F. A., \& Hewitt, P. L. (1994). Dimensions of perfectionism and constructive thinking as a coping response. Journal of Rational-Emotive and CognitiveBehavior Therapy, 12, 163-179.

Frost, R. O., Marten, P., Lahart, C., \& Rosenblate, R. (1990). The dimensions of perfectionism. Cognitive Therapy and Research, 14, 449-468.

Gaudreau, P. (2016). The 2 x 2 model of perfectionism in sport, dance, and exercise. In A. P. Hill (Ed.), The Psychology of Perfectionism in Sport, Dance, and Exercise (pp. 174200). London: Routledge.

Greenspon, T. S. (2000). "Healthy Perfectionism" is an oxymoron! Reflections on the psychology of perfectionism and the sociology of science. The Journal of Secondary Gifted Education, 11, 197-208.

Greenspon, T. S. (2008). Making sense of error: A view of the origins and treatment of perfectionism. American Journal of Psychotherapy, 62, 263-282.

Hall, H. K. (2006). Perfectionism: A hallmark quality of world class performers, or a psychological impediment to athletic development? In D. Hackfort \& G. Tenenbaum (Eds.), Perspectives in Sport and Exercise Psychology; Essential Processes for Attaining Peak Performance (vol. 1, pp. 178-211). Oxford, UK: Meyer \& Meyer Publishers.

Hall, H. K. (2016). Reflections on perfectionism and its influence on motivational processes in sport dance, and exercise. In A. P. Hill (Ed.), The Psychology of Perfectionism in Sport, Dance, and Exercise (pp. 275-295). London: Routledge.

Hall, H. K., Hill, A. P., \& Appleton, P. R. (2012). Perfectionism: A foundation for sporting excellence or an uneasy pathway toward purgatory? In R. C. Roberts \& D. Treasure 
(Eds.), Advances in Motivation in Sport and Exercise (pp. 129-168). Champaign, IL: Human Kinetics Publishers.

Hall, H. K., Hill, A. P., Appleton, P. R., \& Kozub, S. A. (2009). The mediating influence of unconditional self-acceptance and labile self-esteem on the relationship between multidimensional perfectionism and exercise dependence. Psychology of Sport and Exercise, 10, 35-44.

Hewitt, P. L., \& Flett, G. L. (1991). Perfectionism in the self and social contexts: Conceptualization, assessment, and association with psychopathology. Journal of Personality and Social Psychology, 60, 456-470.

Hewitt, P. L., \& Flett, G. L. (2007). When Does Conscientiousness Become Perfectionism? Traits, Self-Presentation Styles, and Cognitions Suggest a Persistent Psychopathology. Current Psychiatry, 6, 49.

Hill, A. P. (2013). Perfectionism and athlete burnout: A test of the $2 \times 2$ model of dispositional perfectionism. Journal of Sport and Exercise Psychology, 35, 18-29.

Hill, A. P. (2014). Perfectionistic strivings and the perils of partialling. International Journal of Sport and Exercise Psychology, 12, 302-315.

Hill, A. P. \& Curran, T. (2016). Perfectionism and burnout: A meta-analysis. Personality and Social Psychological Review. 20, 269-288.

Hill, A. P. \& Davis, P.A. (2014). Perfectionism and emotion regulation in coaches: A test of the $2 \times 2$ model of dispositional perfectionism. Motivation and Emotion, 38, 715-726. 
Hill, A. P., Hall, H. K., \& Appleton, P. R. (2010). A comparative examination of the correlates of self-oriented perfectionism and conscientious achievement striving in male junior elite cricketers. Psychology of Sport and Exercise, 11, 162-168.

Hill, A. P., Hall, H. K., \& Appleton, P. R. (2012). An assessment of the similarities between a measure of positive perfectionism and a measure of conscientious achievement striving. Psychology of Sport and Exercise, 13, 353-359.

Hill, A. P., Hall, H. K., Appleton, P. R. \& Kozub, S. A. (2008). Perfectionism and burnout in junior elite soccer players: The mediating influence of unconditional self-acceptance. Psychology of Sport and Exercise. 9, 630-644.

Hill, A. P., Hall, H. K., Appleton, P. R. \& Murray, J. J. (2010). Perfectionism and burnout in canoe polo and kayak slalom athletes: The mediating influence of validation and growth-seeking. The Sport Psychologist, 24, 16-34.

Jowett, G. E., Mallinson, S. H., \& Hill, A. P. (2016). An independent effects approach to perfectionism in sport, dance, and exercise. In A. P. Hill (Ed.), The Psychology of Perfectionism in Sport, Dance, and Exercise (pp. 85-149). London: Routledge.

Lynam, D. R., Hoyle, R. H., \& Newman, J. P. (2006). The perils of partialling cautionary tales from aggression and psychopathy. Assessment, 13, 328-341.

Madigan, D. J., Stoeber, J., \& Passfield, L. (2015). Perfectionism and burnout in junior athletes: A three-month longitudinal study. Journal of Sport \& Exercise Psychology, $37,305-315$.

Madigan, D. J., Stoeber, J., \& Passfield, L. (2016). Perfectionism and attitudes towards doping in junior athletes. Journal of Sports Sciences, 34, 700-706. 
Missildine, W. H. (1963). Your Inner Child of the Past. New York, NY: Simon and Schuster.

Molnar, D. S., Sadava, S. W., Flett, G. L., \& Colautti, J. (2012). Perfectionism and health: A mediational analysis of the roles of stress, social support and health-related behaviours. Psychology and Health, 27, 846-864.

Powers, T. A., Koestner, R., Zuroff, D. C., Milyavskaya, M., \& Gorin, A. A. (2011). The effects of self-criticism and self-oriented perfectionism on goal pursuit. Personality and Social Psychology Bulletin, 37, 964-975.

Rice, K. G., Richardson, C. M., \& Ray, M. E. (2016). Perfectionism in academic settings. In F. Sirois \& D. S Molnar (Eds.), Perfectionism, Health, and Well-Being (pp. 245-264). Springer International Publishing.

Scott, J. (2007). The effect of perfectionism and unconditional self-acceptance on depression. Journal of Rational-Emotive \& Cognitive-Behavior Therapy, 25, 35-64.

Sirois, F. M., \& Molnar, D. S. (2016). Conceptualizations of Perfectionism, Health, and Well-Being: An Introductory Overview. In F. Sirois \& D. S Molnar (Eds.), Perfectionism, Health, and Well-Being (pp. 1-21). Springer International Publishing.

Smith, M. M., Saklofske, D. H., Stoeber, J., \& Sherry, S. B. (in press). The Big Three Perfectionism Scale: A new measure of perfectionism. Journal of Psychoeducational Assessment.

Smith, M. M., Sherry, S. B., Rnic, K., Saklofske, D. H., Enns, M., \& Gralnick, T. (2016). Are perfectionism dimensions vulnerability factors for depressive symptoms after controlling for neuroticism? A Meta-analysis of 10 Longitudinal Studies. European Journal of Personality, 30, 201-212. 
Stairs, A. M., Smith, G. T., Zapolski, T. C., Combs, J. L., \& Settles, R. E. (2011). Clarifying the construct of perfectionism. Assessment, 19, 146-166.

Stoeber, J. (2011). The dual nature of perfectionism in sports: Relationships with emotion, motivation, and performance. International Review of Sport and Exercise Psychology, $4,128-145$.

Stoeber, J. (2016). Comparing two short forms of the Hewitt-Flett Multidimensional Perfectionism Scale. Assessment.

Stoeber, J., \& Damian, L. (2016). Perfectionism in employees: Work engagement, workaholism, and burnout. In F. M. Sirois \& Molnar, D. S. (Eds.), Perfectionism, Health, and Well-Being (pp. 265-283). New York: Springer.

Stoeber, J., \& Gaudreau, P. (2017). The advantages of partialling perfectionistic strivings and perfectionistic concerns: Critical issues and recommendations. Personality and Individual Differences, 104, 379-386.

Stoeber, J., Kempe, T., \& Keogh, E. J. (2008). Facets of self-oriented and socially prescribed perfectionism and feelings of pride, shame, and guilt following success and failure. Personality and Individual Differences, 44, 1506-1516.

Stoeber, J., Kobori, O., \& Brown, A. (2014). Examining mutual suppression effects in the assessment of perfectionism cognitions evidence supporting multidimensional assessment. Assessment, 21, 647-660.

Stoeber, J., \& Otto, K. (2006). Positive conceptions of perfectionism: approaches, evidence and challenges. Personality and Social Psychology Review, 10, 295-319. 
Thompson, R., \& Zuroff, D. C. (2004). The Levels of Self-Criticism Scale: Comparative selfcriticism and internalized self-criticism. Personality and Individual Differences, 36, 419-430. 
Figure 1. Venn diagram representing the shared variance of perfectionistic strivings (PS), perfectionistic concerns (PC), and an outcome variable (Y). Partialling controls for the shared variance of PS and PC indicated by $\mathrm{a}+\mathrm{d}$ and uncovers the unique relations that PS (indicated by b) and PC (indicated by c) have with Y. Reprinted from Personality and Individual Differences, 104, J. Stoeber \& P. Gaudreau, The advantages of partialling perfectionistic strivings and perfectionistic concerns: Critical issues and recommendations, 379-386, Copyright Elsevier (2016).

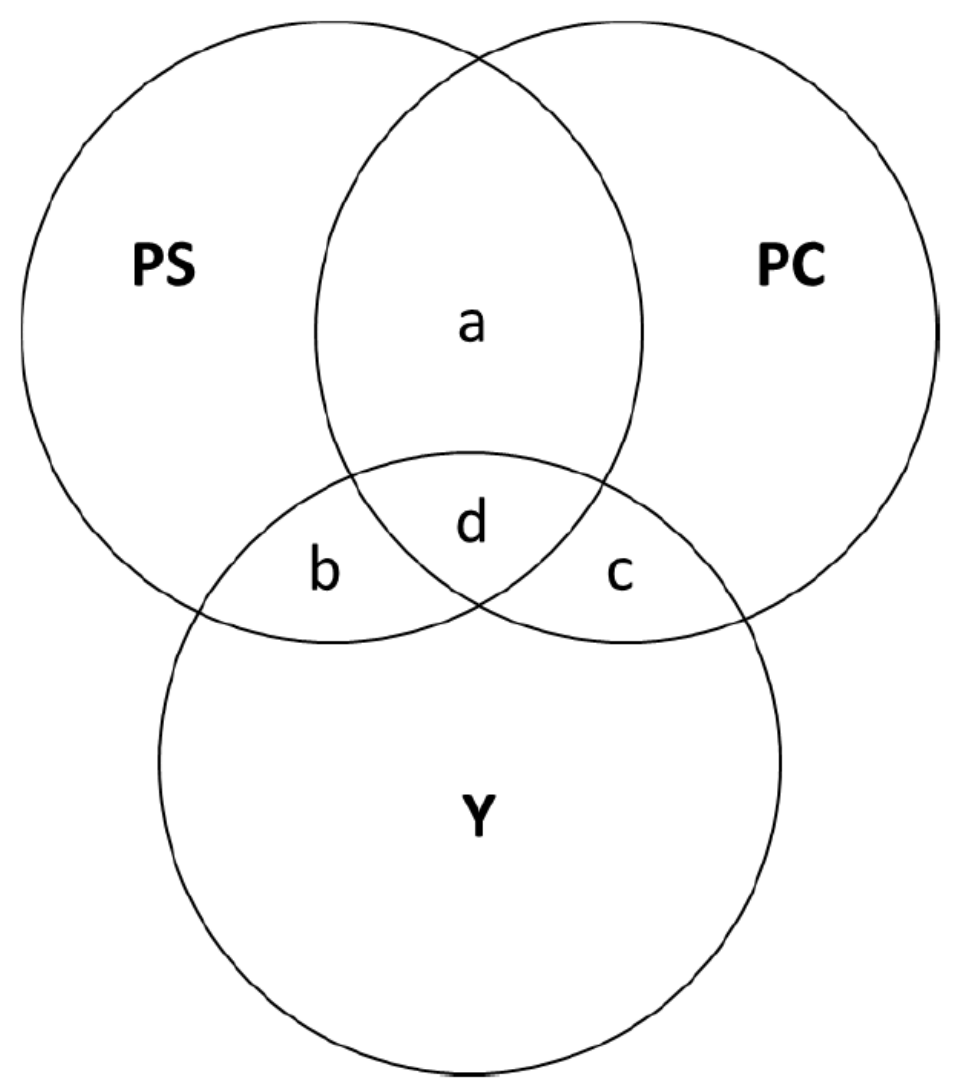

